\title{
An introduction to ethical theory for healthcare assistants
}

\section{Daniel Rodger, Lecturer, School of Health and Social Care, London South Bank University; and Bruce Blackshaw, Doctoral Student, School of Philosophy, Theology and Religion, University of Birmingham}

Abstract
This article will explore and summarise
the four main ethical theories that have
relevance for healthcare assistants. These
are: utilitarianism, deontology, virtue ethics
and principlism. Understanding different
ethical theories can have a number of
significant benefits, which have the
potential to shape and inform the care of
patients, challenge bad practice and lead
staff to become better informed about areas
of moral disagreement.
Keywords
- Ethical theory
- Utilitarianism
- Deontology
- Virtue ethics
- Principlism
- Nursing ethics
- Bioethics

$\mathbf{H}$ ealthcare assistants (HCAs) do not receive any mandatory training in ethical theory. This has the potential to result in poor ethical decision-making, and be an obstacle to understanding and appreciating the diversity of moral views between patients and colleagues. Here we explore the four most prominent ethical theories in healthcare ethics that inform peoples' actions and beliefs (whether they are aware of it or not), from everyday moral decisions to more abstract ethical dilemmas: utilitarianism, deontology, virtue ethics and principlism. Although other approaches to ethics do exist, an introduction to these four will provide a good foundation from which to explore the topic further.

Some HCAs may question if understanding ethical theory has any

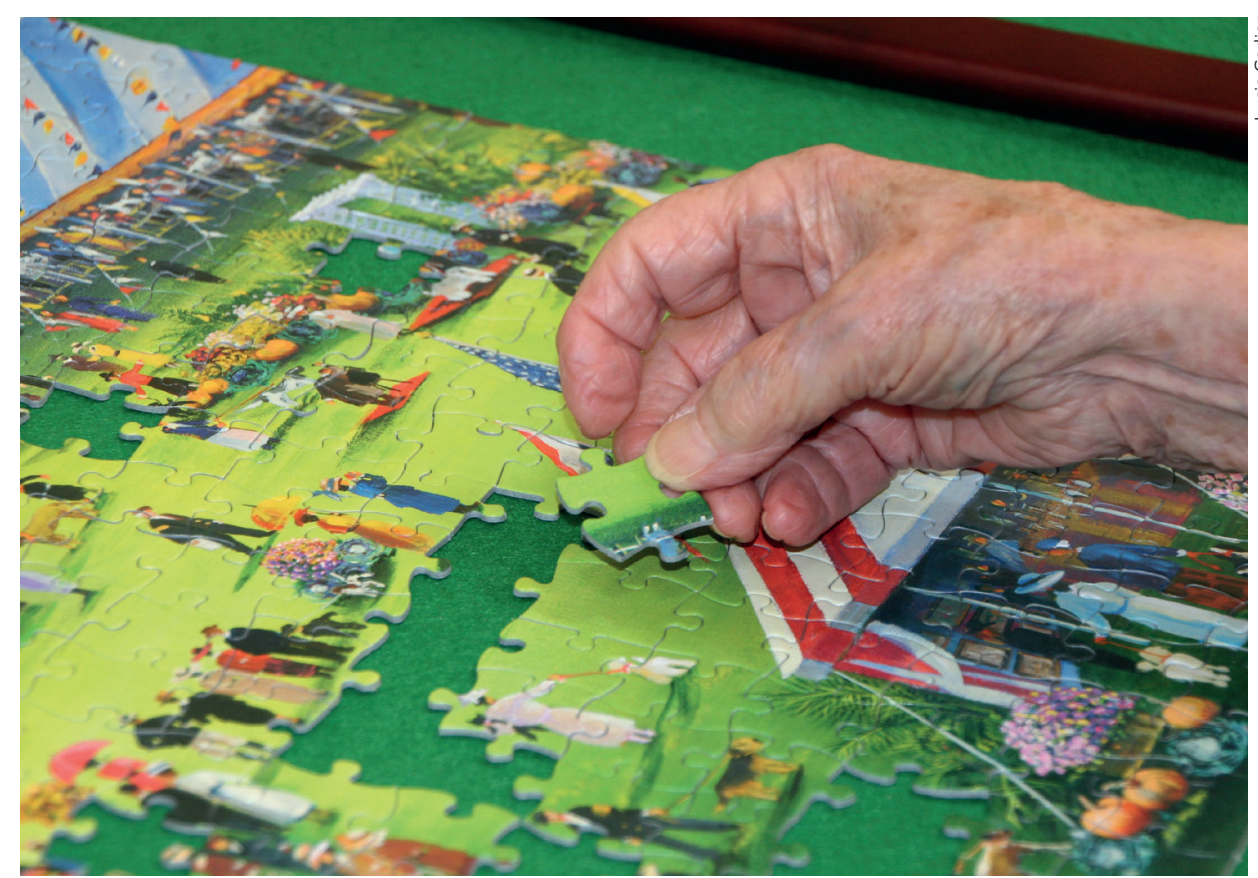

HCAs may question if understanding ethical theory has any real world application for them and their practice.

real world application for them and their practice. However, there are several good reasons for doing so. First, understanding ethical theory helps inform ethical decision-making. Second, it improves confidence and competence for making future ethical decisions. Third, it helps to understand how and why patients or colleagues may not share the same moral outlook. Fourth, it can increase an HCA's ability to correctly identify moral problems and obstacles to good practice in the workplace.

Ethical theory can be difficult to understand because it can appear abstract and irrelevant to everyday practice; but it need not be. An easy way to think of ethical theory is to see it simply as the attempt to identify and classify moral standards or rules that should, or do, guide our behaviour (Hendricks, 2004).
Although there is a technical difference between the terms 'ethical' and 'moral', they will be used interchangeably throughout this article.

\section{Utilitarianism}

Utilitarianism is a widely adopted moral theory that is the best-known example of consequentialism, a class of moral theories that are solely concerned about the consequences of our actions-whether they bring about the desired results. In effect, the end justifies the means.

The basic concept has been around for millennia: an example is in the New Testament (Holy Bible, New International Version, 1984), where the high priest, Caiaphas, advises the Jewish council to have Jesus killed, stating it is better for you that one man die for the people than that the whole nation 
perish' (John 11:50). More recently, utilitarianism was advanced by the English social reformers Jeremy Bentham and his student, John Stuart Mill, in the 18th and 19th centuries (Avery, 2017).

In utilitarianism, morally good actions are those that bring about an increase in states such as pleasure, happiness or wellbeing, known as 'utility'. Actions are not regarded as good in themselves, but good only so far as they increase 'utility'. An act is considered right if it brings about more pleasure than pain, and wrong if it produces more pain than pleasure. Morally right acts are those that maximise (increase) utility-and maximise it for everyone, not just individuals. This is often expressed as 'the greatest happiness for the greatest number'.

One attraction of utilitarianism is its simplicity. As a single principle to guide our actions, it can potentially answer any moral question. It also seems to get to the heart of what we feel morality should be about-promoting human flourishing (meaning living well) and avoiding suffering. The NHS, for instance, could be said to operate under utilitarian principles, because it intends to use its resources to produce the greatest benefit for the greatest number of people.

There are, however, at least two major problems with utilitarianism. One is the difficulty in calculating the maximum utility for a given action. For example, it is not clear whether it is better for one individual to have a significant increase in happiness, or for many individuals to have a small increase in happiness. It is also difficult to foresee the consequences for a particular action and the consequences we expect do not always materialise.

A more significant objection is that utilitarianism allows injustice. In principle, a healthy person could be killed in order that their organs be used to save five patients in need of transplants, as this produces five healthy, happy people for the cost of one. Innocent people can be sacrificed for the greater good of humanity. Provided utility is maximised, this might justify various horrendous deeds.

Of course, utilitarians have responses to these objections. For example, they could maintain that the principle of justice will usually produce the best results (i.e. maximum utility). For this reason, it should be made a moral rule,

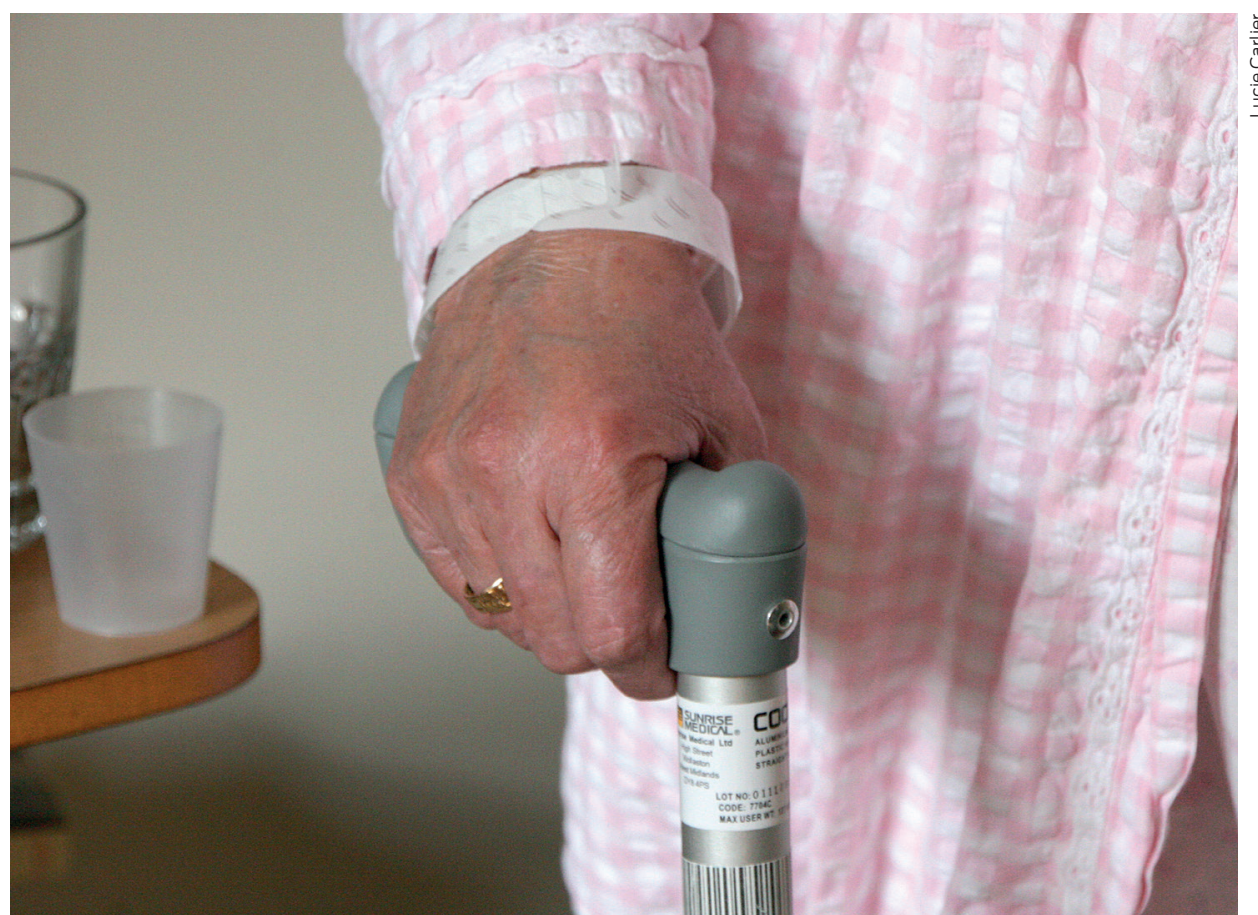

Ethical theory can appear abstract and irrelevant to everyday practice; but it need not be.

\section{Box 1. Four ways of thinking about right and wrong}

\section{Utilitarianism}

An act is considered right if it brings about more pleasure than pain, and wrong if it produces more pain than pleasure.

Deontology

There are certain duties that are intrinsically good and must be followed to act morally. There are also certain actions that are intrinsically wrong, and these must be refrained from, even if it can be foreseen that they will result in good.

\section{Virtue ethics}

What matters most is acquiring good character; by developing good character-acquiring certain virtues-one will act appropriately.

\section{Principlism}

Four ethical principles-autonomy, beneficence, non-maleficence and justice-help structure moral thinking and inform ethical decision-making.

because this will mean more people will follow it. If more people follow it, the result will be more utility. The calculation problem can also be largely dealt with by using rules that are known to maximise utility in most situations. This reduces the need to calculate utility for a particular action. Utilitarianism (being a consequentialist theory) emphasises the consequences of people's actions and it is the consequences alone that determine whether that act or behaviour was right or wrong. From this standpoint, HCAs must be careful to consider what the foreseen and unforeseen consequences of their actions might be.

\section{Deontology}

In utilitarianism, the moral rightness of an action is determined solely by its consequences. Deontology, by contrast, is concerned with certain features of an 


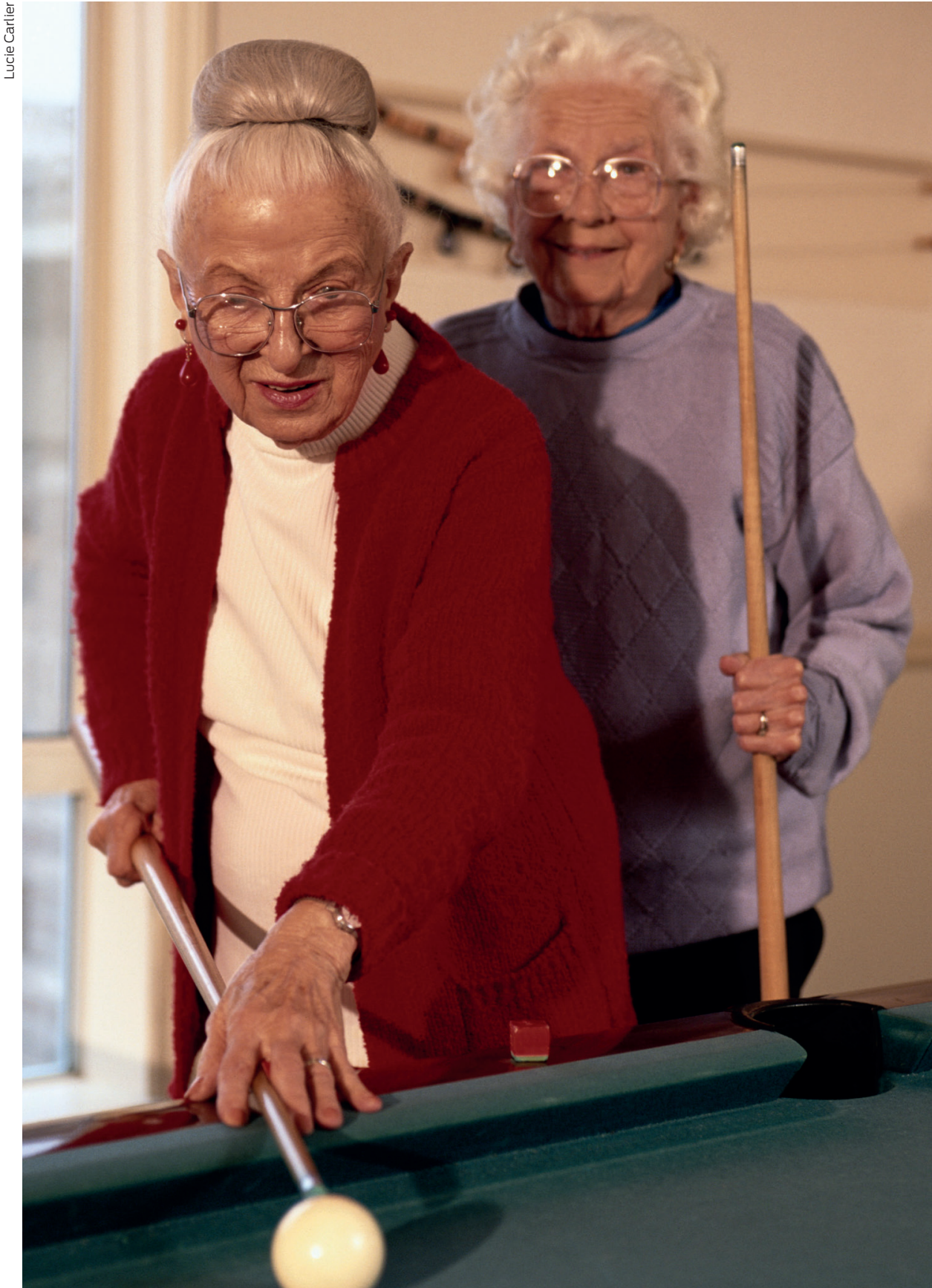

HCAs must be careful to consider what the foreseen and unforeseen consequences of their actions might be.

action itself. The end is never justified by the means; 'some choices cannot be justified by their effects-that no matter how morally good their consequences, some choices are morally forbidden' (Alexander and Moore, 2016).

Deontological systems are built on the belief that there are certain duties, or rules, that are intrinsically good and must be followed to act morally. There are also certain actions that are intrinsically wrong, and these must be refrained from, even if it can be foreseen that they will result in good, or if refusing to do them will result in harm. Doing the right thing takes priority over achieving good things. A well-known example of a deontological system is the Universal Declaration of Human Rights (UN General Assembly, 1948), which states that certain actions such as torture are intrinsically wrong (Plomer, 2005).

The best-known deontological system is that of Immanuel Kant (1724-1804), one of the most important European philosophers of all time. Kant's aim was to use reason to determine our moral principles, and he developed a single rule called the 'categorical imperative', by which all other moral principles are to be judged. In one form, the categorical imperative says that we should act only according to rules that we consider could be made universal, i.e. applicable to everyone. For example, should I make a false promise to repay money? The categorical imperative asks: what would happen if everyone acted in this way? Clearly, it would render promises worthless, and so by Kant's criteria, making false promises is wrong.

Deontological systems have an advantage over utilitarianism in that they usually imply many scenarios that seem intuitively wrong are immoral (such as sacrificing one person to obtain their organs for the benefit of many). This may be because their rules are originally derived from our common moral intuitions. Of course, this can turn to disadvantage in catastrophic situations, such as where torturing one person is required to save one million people.

Deontology has considerable relevance to HCAs. Patients have certain human rights that must be considered in their treatment, such as the right to privacy and dignity, and the right to consent. HCAs also have a code of conduct that encapsulates their moral and clinical duties (Skills for Care and Skills for Health, 2013). For example, HCAs are bound to always act in the best interests of their patients, and to treat them with respect and compassion. It is essential that HCAs are familiar with their code of conduct, as it is a valuable guide to what is expected of them by their patients.

\section{Virtue ethics}

Virtue ethics (VE) is considered to be the oldest of the four ethical theories we are exploring, owing its origins to Aristotle back in the fourth century BC and further developed by Thomas Aquinas in the thirteenth century (Avery, 2017). In the past several decades, VE has become increasingly prominent and is now considered to have genuine application

\section{"Deontology: patients have certain human rights that must be considered in their treatment, such as the right to privacy and dignity, and the right to consent"}


for those working in the frontline of healthcare. What distinguishes virtue ethics from the other ethical theories is that it is less concerned with what we do (action) and more so with who we become (character) over time (Talbot, 2012). What matters most is acquiring good character; by developing good character one will act appropriately; doing the right thing for the right reason when required.

According to VE, doing the right thing is not about following a set of rules (deontology) or trying to bring about the most pleasure or happiness (utilitarianism)-it is about becoming the right sort of person by seeking to acquire certain virtues. A virtue is a type of good disposition (or tendency) to act in one way instead of another; for instance, if a colleague is mistreating a patient, an HCA ought to act courageously and confront them about their actions. If someone has the virtue of courage, they will do what is right when it is demanded of them. If someone lacks the virtue of courage, then they ought to practise being courageous when the situation demands it, until they acquire the disposition to respond courageously and it becomes almost 'second nature' to them.

Virtues are dispositions of character that people can acquire with practice over time, which can be difficult, in the same way that forming any new habit is. It is through trying to form virtuous habits that virtuous character develops and stabilises through the process of habituation (the process of acquiring new habits) with practice and reflection (Chadwick and Gallagher, 2016).

Aristotle (2004) described a virtue as the mean between two extremes. So courage, for example, is the mean or balance between cowardice (deficiency) and being rash (excess). Therefore, it is not enough just to know that courage is good, but also to think about being courageous and trying to acquire it as part of your character. Virtues that play a significant part in the role of the HCA include: trustworthiness, integrity, compassion and respectfulness. VE challenges HCAs to think about what makes a good HCA: 产 what should they know? What virtues are needed to promote the wellbeing of their patients and colleagues?

The good or virtuous HCA is the one who acquires the moral and intellectual

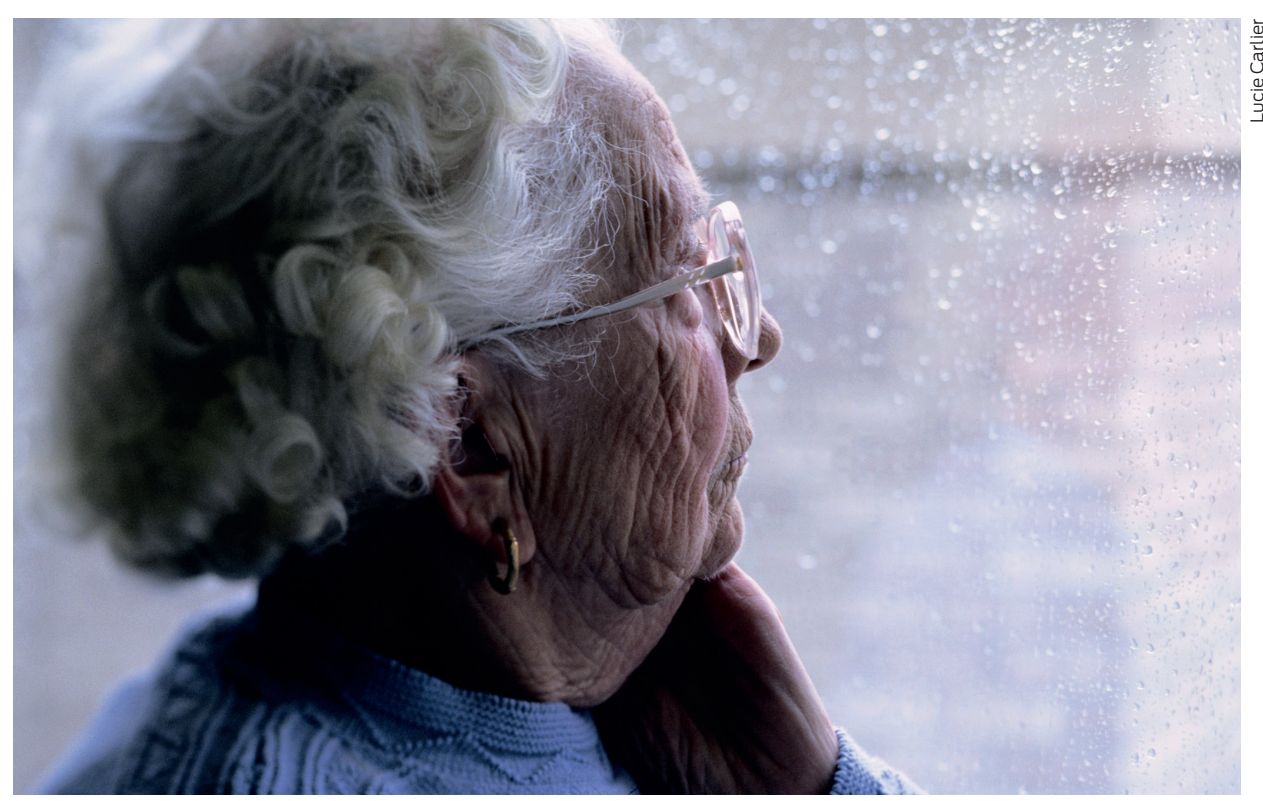

Patients have certain human rights that must be considered in their treatment, such as the right to privacy and dignity, and the right to consent.

virtues that make them flourish in their role. By good, Aristotle meant that something functions as it ought to; so a good knife would be one that cuts easily with minimal effort. The purpose of a knife is therefore to cut and so the overarching purpose of the HCA is to care for their patients and to help them flourish: to promote their wellbeing. As an HCA, there are numerous ways to pursue the virtues; for instance, you can read about and study them, and you can learn from the virtues exemplified by colleagues who you might aspire to be like one day. It is also possible to learn from patients as they struggle with illness or imminent death, yet who nevertheless demonstrate courage, perseverance and kindness, in spite of their circumstances (Campbell, 2013).

VE is not without criticism; one of the perceived problems is that it does not seem to offer any obvious moral rule for right action. A utilitarian could simply state that you ought to always act so that you produce the greatest good with the least harm. Developing such a rule for $\mathrm{VE}$ is more challenging. An example of one such rule would be the following: 'An action is right if and only if it is what an agent with a virtuous character would do in the circumstances' (Oakley and Cocking, 2004:9). For example, it would be right to pick up the purse of a patient who had unknowingly dropped it and to return it to them, because this is what someone with the virtue of benevolence (kindness) would do. The real challenge of VE for HCAs is that it encourages them to be concerned about more than being seen to do the right thing. Instead, it asks that they pursue the sort of character that will promote the wellbeing of themselves, their colleagues and their patients.

\section{Principlism}

Although principlism is not strictly an ethical theory, it is the most widely used moral framework for guiding conduct in

"In virtue ethics, what
matters most is acquiring
good character; by
developing good character
one will act appropriately;
doing the right thing for the
right reason when required.
Doing the right thing is
not about following a set
of rules or trying to bring
about the most pleasure
or happiness-it is about
becoming the right sort
of person by seeking to
acquire certain virtues"




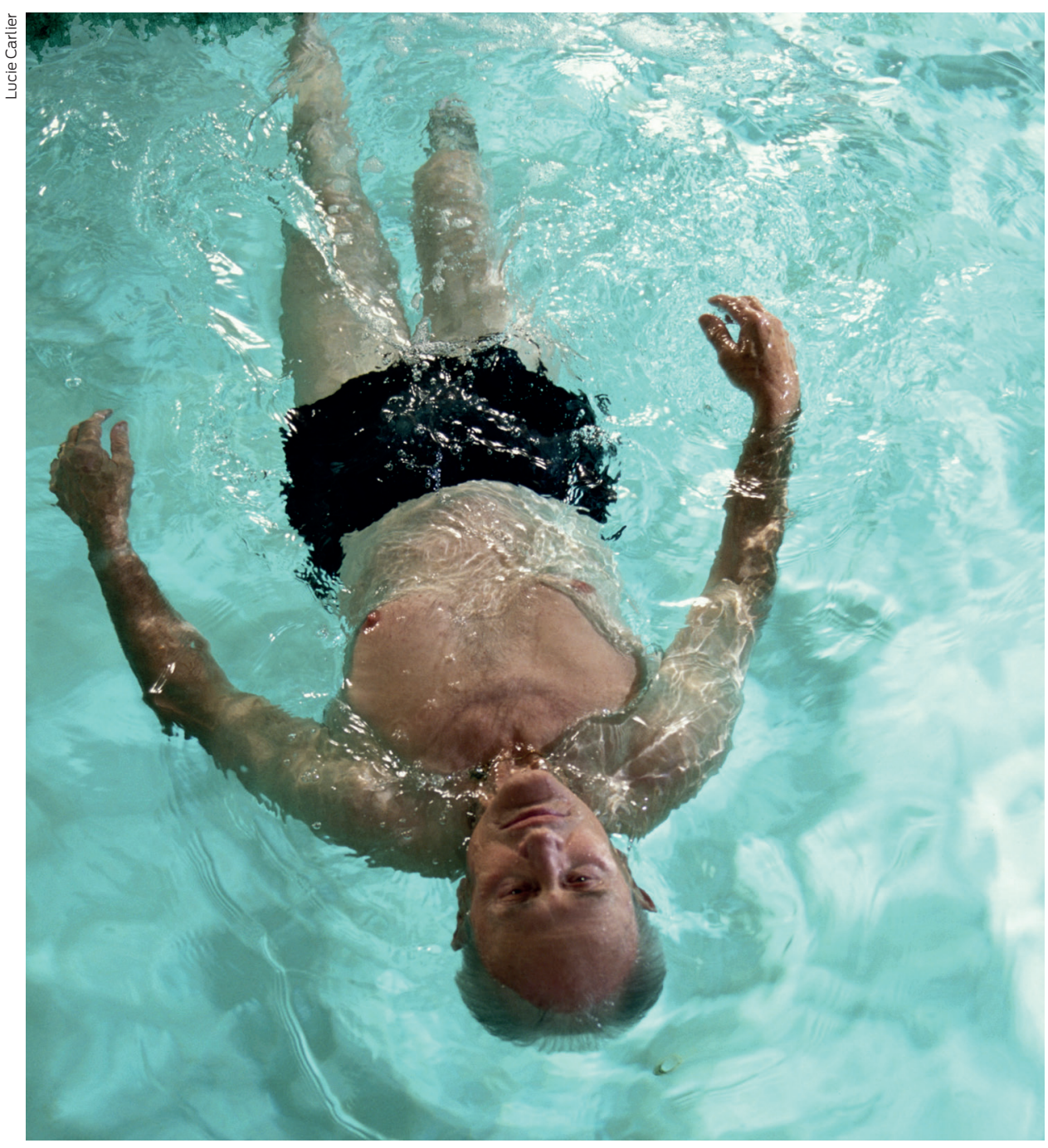

HCAs are bound to act in the best interests of their patients, and to treat them with respect and compassion.

healthcare, and is clearly relevant to the HCA. Beauchamp and Childress (2013) first described its four ethical principles as a way to help structure moral thinking and to inform ethical decisionmaking. The principles are: autonomy,

\section{"The four principles of 'principlism'-autonomy, beneficence, non-maleficence and justice-arebased upon 'common morality', which describes the types of moral values most people accept as having relevance and importance to their moral lives"}

beneficence, non-maleficence and justice. The order of the four principles does not represent any significance of one principle over another. Although autonomy is the first, it is no more important than the other three principles (Campbell, 2012).

The strength of this approach is that the four principles are based upon what Beauchamp and Childress (2013) call 'common morality', which describes the types of moral values that most people accept as having relevance and importance to their moral lives. This 'common morality' is generally subscribed to by people, irrespective of their cultural or religious background, which may explain its popularity in the diverse area of healthcare.

The four principles draw on aspects of all three moral theories discussed so far in an attempt to provide a practical approach to moral decision-making. The first principle is autonomy, and describes the importance of letting patients make their own decisions about their care. So an HCA must respect the choices a patient makes about their care, whether they agree with it or not; the decision must remain his or hers alone.

The second principle is beneficence; this means making sure that whatever an HCA does, they are considering what will benefit the patient; the goal is always to do good.

The third principle is non-maleficence, which means to avoid doing patients harm, whether through the actions or inaction of an HCA; the goal is always to minimise any unnecessary harm to patients or colleagues. Some harm is unavoidable; for instance, an HCA may have to take a patient for blood test and although it may hurt (cause harm), the intention is to benefit the patient and improve their treatment. This principle intends to make sure that the patient is not experiencing any type of avoidable or unnecessary harm or suffering.

The fourth principle is justice. It describes the importance of treating people fairly, making sure that noone is receiving more favourable treatment than another or is being discriminated against. This means actively treating all patients and colleagues with dignity, respect and compassion at all times, as demanded of HCAs in their code of conduct (Skills for Care and Skills for Health, 2013).

Campbell (2012) points out that healthcare workers can be tempted to use the four principles approach like a formula, because of the common use of mnemonics such as the 'airway, breathing, circulation, disability, exposure (ABCDE)' approach to treating patients.

However, although the four principles can be easily memorised, they are not intended to be used as a moral formula to calculate what an HCA should or should not do. Rather, they are important moral principles that should be considered.

Principlism is not without its problems; the principles are open to a wide range of conclusions, depending on the emphasis placed on one principle over another, and are liable to producing contradictions which cannot be easily resolved (Herring 2014). Nevertheless, ethical principlism does provide the HCA with some very helpful moral principles to consider, as they seek to provide the very best care and environment for their patients. 


\section{Conclusion}

In this article, we have sought to summarise and contextualise the main ethical theories and thought that have relevance to HCAs. Incorporating knowledge of ethical theory into practice can contribute to better quality patient care and relationships with patients and colleagues. In a diverse culture such as our own, understanding how and why other people do not share the same moral views has never been so essential. Having an appreciation for different ethical theories is one way to understand the diversity of opinion on moral matters.

Each ethical theory has its own strengths and weaknesses and yet each of them challenges a different facet of what it means to be a good HCA and to do what is right. Utilitarianism highlights the importance of trying to understand the consequences of our actions and how they might affect us, our patients and colleagues. Deontology challenges us to make sure that we always treat patients, their family members and colleagues with dignity and respect and to value integrity. Virtue ethics challenges the focus on just trying to do the right thing and instead encourages us to consider the sort of person we are becoming and what it means to be a good HCA. Finally, principlism borrows aspects of all three ethical theories and emphasises the need to respect each patient's decisions and as far as possible to always act in the patient's best interest.

It is therefore vital to reflect on your own practice and appreciate how different approaches to ethics affect and shape the care that your patients receive. This introduction to ethical theory may also be of benefit to nursing associates, allied health and nursing students. BJHCA

\section{References}

Alexander L, Moore M (2016) Deontological ethics. In: The Stanford Encyclopedia of Philosophy, Zalta EN, Nodelman U, Allen C et al, eds. https://plato. stanford.edu/archives/win2016/entries/ethicsdeontological/ [accessed 13 September 2017] Aristotle (2004) The Nicomachean Ethics. Penguin Books, London

Avery G (2017) Law and Ethics in Nursing and Healthcare. 2nd edn. Sage, London

Beauchamp TL, Childress JF (2013) Principles of Biomedical Ethics. 7th edn. Oxford University Press, Oxford

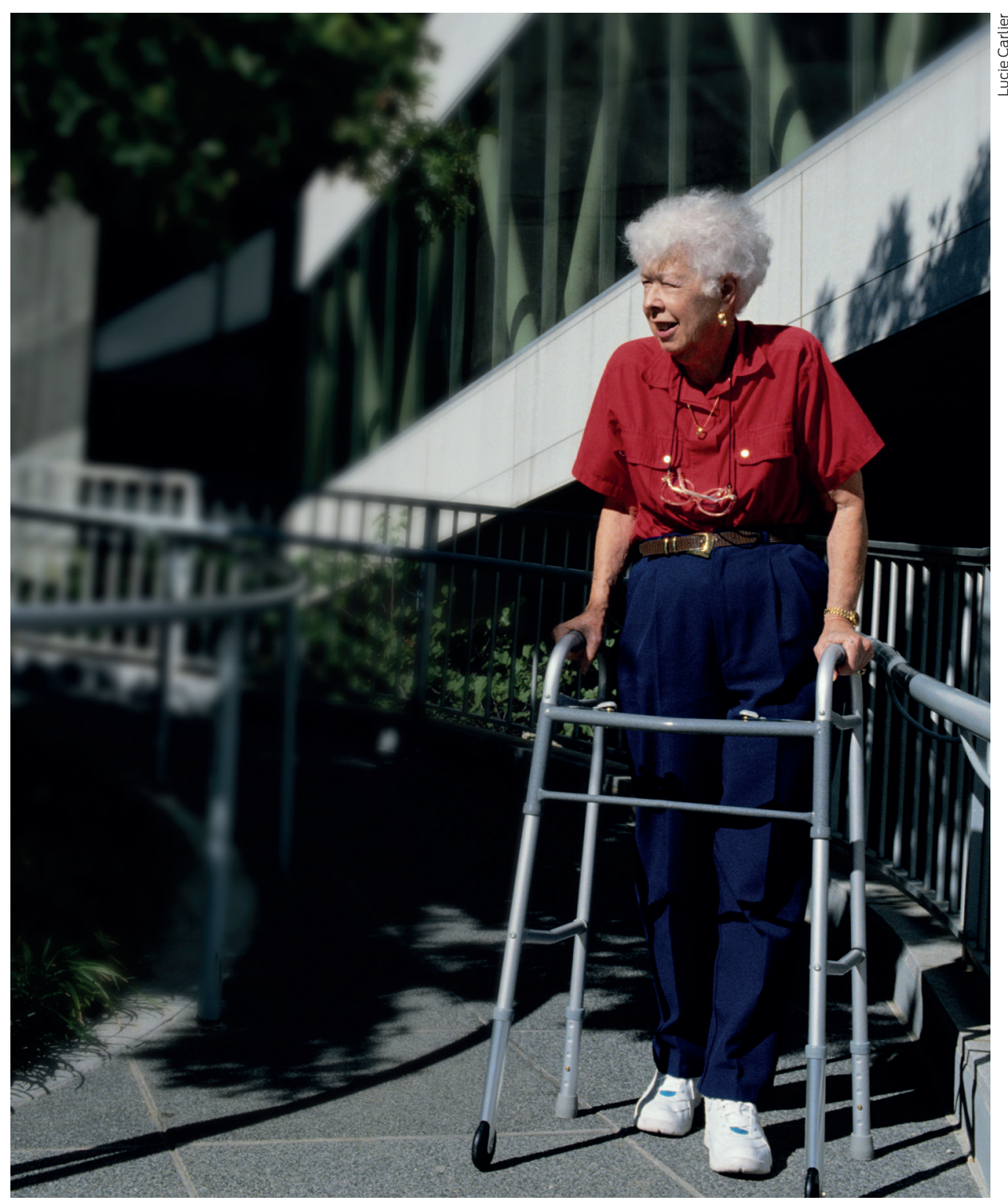

An HCA must respect the choices a patient makes about their care, whether they agree with it or not.
Campbell AV (2013) Bioethics the Basics.

Routledge, London

Chadwick R, Gallagher A (2016) Ethics and Nursing Practice. 2nd edn. Palgrave, London

Hendricks J (2004) Law and Ethics: Foundations in Nursing and Health Care. Nelson Thornes, Cheltenham.

Herring J (2014) Medical Law and Ethics. 5th edn. Oxford University Press, Oxford

Oakley J, Cocking D (2008) Virtue Ethics and

Professional Roles. Cambridge University Press, Cambridge

Plomer A (2005) The Law and Ethics of Medical
Research: International Bioethics and Human Rights. Cavendish Publishing, London

Talbot M (2012) Bioethics: An Introduction. Cambridge University Press, Cambridge

The Holy Bible, New International Version (1984)

Zondervan House, Grand Rapids MI

Skills for Care and Skills for Health (2013) Code of Conduct for Healthcare Support Workers and Adult Social Care Workers in England. http:// tinyurl.com/oa29qda (accessed 11 September 2017)

UN General Assembly (1948) Universal declaration of Human Rights (217 [III] A). UN, Paris.

\section{Reflective questions for your continuing professional development (CPD)}

- Reflect about what it means to be a good HCA

- Why is it important to understand the views of those who disagree with you?

Is it important to aspire to be a good HCA?

- Does one ethical theory seem more relevant to your practice than the others?

- How should you manage moral disagreement with a patient or colleague? 